\title{
Box-ticking and Olympic high jumping - Physicians' perceptions and acceptance of national physician validation systems
}

Citation for published version (APA):

Sehlbach, C., Govaerts, M. J. B., Mitchell, S., Rohde, G. G. U., Smeenk, F. W. J. M., \& Driessen, E. W. (2018). Box-ticking and Olympic high jumping - Physicians' perceptions and acceptance of national physician validation systems. Medical Teacher, 40(9), 886-891. https://doi.org/10.1080/0142159X.2018.1470320

Document status and date:

Published: 01/01/2018

DOI:

10.1080/0142159X.2018.1470320

Document Version:

Publisher's PDF, also known as Version of record

\section{Document license:}

Taverne

Please check the document version of this publication:

- A submitted manuscript is the version of the article upon submission and before peer-review. There can be important differences between the submitted version and the official published version of record.

People interested in the research are advised to contact the author for the final version of the publication, or visit the DOI to the publisher's website.

- The final author version and the galley proof are versions of the publication after peer review.

- The final published version features the final layout of the paper including the volume, issue and page numbers.

Link to publication

\footnotetext{
General rights rights.

- You may freely distribute the URL identifying the publication in the public portal. please follow below link for the End User Agreement:

www.umlib.nl/taverne-license

Take down policy

If you believe that this document breaches copyright please contact us at:

repository@maastrichtuniversity.nl

providing details and we will investigate your claim.
}

Copyright and moral rights for the publications made accessible in the public portal are retained by the authors and/or other copyright owners and it is a condition of accessing publications that users recognise and abide by the legal requirements associated with these

- Users may download and print one copy of any publication from the public portal for the purpose of private study or research.

- You may not further distribute the material or use it for any profit-making activity or commercial gain

If the publication is distributed under the terms of Article $25 \mathrm{fa}$ of the Dutch Copyright Act, indicated by the "Taverne" license above, 


\section{Medical Teacher}

\section{Box-ticking and Olympic high jumping - Physicians' perceptions and acceptance of national physician validation systems}

Carolin Sehlbach, Marjan J. B. Govaerts, Sharon Mitchell, Gernot G. U. Rohde, Frank W. J. M. Smeenk \& Erik W. Driessen

To cite this article: Carolin Sehlbach, Marjan J. B. Govaerts, Sharon Mitchell, Gernot G. U. Rohde, Frank W. J. M. Smeenk \& Erik W. Driessen (2018) Box-ticking and Olympic high jumping Physicians' perceptions and acceptance of national physician validation systems, Medical Teacher, 40:9, 886-891, DOI: 10.1080/0142159X.2018.1470320

To link to this article: https://doi.org/10.1080/0142159X.2018.1470320

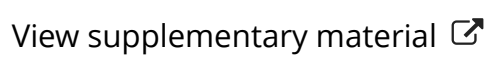

Published online: 24 May 2018.

Submit your article to this journal

III Article views: 412

Q View related articles $\asymp$

View Crossmark data $₫$

Citing articles: 3 View citing articles 


\title{
Box-ticking and Olympic high jumping - Physicians' perceptions and acceptance of national physician validation systems
}

\author{
Carolin Sehlbach $^{\mathrm{a}}$ (D), Marjan J. B. Govaerts ${ }^{\mathrm{a}}$, Sharon Mitchell ${ }^{\mathrm{b} *}$, Gernot G. U. Rohde ${ }^{\mathrm{c}}$ (D), \\ Frank W. J. M. Smeenk ${ }^{a, d}$ (ID) and Erik W. Driessen ${ }^{a}$ \\ ${ }^{a}$ Department of Educational Development and Research, School of Health Professions Education, Maastricht University, Maastricht, The \\ Netherlands; 'bepartment of Education, European Respiratory Society, Lausanne, Switzerland; 'Department of Respiratory Medicine, \\ Johann Wolfgang Goethe University Hospital, Frankfurt am Main, Germany; ${ }^{\mathrm{d} D e p a r t m e n t}$ of Respiratory Medicine, Catharina Hospital, \\ Eindhoven, The Netherlands
}

\begin{abstract}
Purpose: National physician validation systems aim to ensure lifelong learning through periodic appraisals of physicians' competence. Their effectiveness is determined by physicians' acceptance of and commitment to the system. This study, therefore, sought to explore physicians' perceptions and self-reported acceptance of validation across three different physician validation systems in Europe.

Materials and methods: Using a constructivist grounded-theory approach, we conducted semi-structured interviews with 32 respiratory specialists from three countries with markedly different validation systems: Germany, which has a mandatory credit-based system oriented to continuing professional development; Denmark, with mandatory annual dialogs and ensuing, non-compulsory activities; and the UK, with a mandatory, portfolio-based revalidation system. We analyzed interview data with a view to identifying factors influencing physicians' perceptions and acceptance.

Results: Factors that influenced acceptance were the assessment's authenticity and alignment of its requirements with clinical practice, physicians' beliefs about learning, perceived autonomy, and organizational support.

Conclusions: Users' acceptance levels determine any system's effectiveness. To support lifelong learning effectively, national physician validation systems must be carefully designed and integrated into daily practice. Involving physicians in their design may render systems more authentic and improve alignment between individual ambitions and the systems' goals, thereby promoting acceptance.
\end{abstract}

\section{Introduction}

Nowadays, many countries have adopted national physician validation systems that differ widely in focus, requirements and procedures (Solé et al. 2014). Yet, they all share a common goal which is to improve quality of care (Archer et al. 2015). To achieve this, all validation processes and procedures are geared towards safeguarding competence and improving performance. While "validation" has a number of alternative expressions (e.g. recertification, revalidation, and maintenance of certification), for the purpose of our study, we selected the term 'national physician validation system' (Horsley et al. 2016).

The effectiveness of a validation system which finds expression in improved practice performance is determined by a physician's commitment to the system. Prior research has suggested that physicians' perceptions of the system, its procedures, the context and outcomes are important determinants of commitment (Lipner et al. 2006; Dubravec 2011). Although several studies have explored physician's perceptions of a single national physician validation system (Goodyear-Smith et al. 2003; Kempkens et al. 2009; Kjaer et al. 2014), none of these, to our knowledge, have explored perceived effectiveness across systems. Hence, the question remains whether and how differences between validation systems affect perceived effectiveness and

\section{Practice points}

- Involving physicians in the design and improvement of physician validation systems can enhance acceptance.

- To prevent credit collection from becoming a tickbox exercise, accredited activities should be embedded in clinical practice.

- Regular, informal meetings between physicians can enhance feedback credibility and increase relatedness and, consequently, acceptance.

- Authentic systems require alignment between requirements and the individuals' goals and motivation, and practice.

reported acceptance of these systems (Brennan et al. 2017) and whether such differences in perceptions, if any, entail a performance change and healthcare quality improvement (Ahmed et al. 2013; Boulet and van Zanten 2014).

The present research seeks to address this question by comparing physicians' perceptions and acceptance of validation across different physician validation systems. To this end, we conducted semi-structured interviews with physicians from three different European countries, using

CONTACT Carolin Sehlbach carolin.sehlbach@maastrichtuniversity.nl E Faculty of Health, Medicine and Life Sciences, Educational Development and Research, Maastricht University, Universiteitssingel 60, 6229 ER Maastricht, The Netherlands

*Sharon Mitchell is currently an independent researcher and no longer affiliated with the European Respiratory Society. 
a constructivist grounded theory approach to analyzing the data.

\section{Methods}

\section{Settings and participants}

Drawing on a previous study on European national physician validation systems (Sehlbach et al. 2018), we chose three countries that differed markedly in their assessment formats and requirements for physician validation: Germany (DE), Denmark (DK), and the United Kingdom (UK) (refer to Supplemental Appendix A for a detailed description of each system). The German system is mandatory and creditbased, consisting of a 5-year repetitive cycle during which period physicians must seek to collect 250 credits. In Denmark, validation takes the form of an annual dialog between physician and employer during which they discuss the physician and institution's needs and related learning needs and activities. Although such dialog is framed as an obligatory, annual development talk, participation in formal educational activities is voluntary. In the UK, by contrast, mandatory annual appraisals constitute the backbone of a 5 -year revalidation cycle. Appraisals are guided by a physician's portfolio that includes information about educational and quality improvement activities undertaken (audits), a systematic evaluation of work delivered (significant events, compliments, and complaints), and peer and patient feedback.

For each country, we purposefully selected practising physicians to reflect diversity in levels of clinical experience and expertise, in experience with the validation system and in settings - by including participants from academic and non-academic hospitals as well as private and public institutions. In employing this sampling strategy, the principal researcher (C. S.) selected participants from a large European database of respiratory physicians, inviting them to participate via e-mail. In case they were unable to participate or deemed themselves unsuitable, participants were asked to suggest colleagues (snowballing) who could offer a distinct view on physician validation. In the end, we interviewed nine German, 11 Danish, and 12 British physicians.

\section{Data collection}

CS conducted all interviews by phone or Skype, either in English or German, which required the Danish interviewees to translate their experiences into English. Interviews lasted between 40 and $70 \mathrm{~min}$, were recorded digitally and transcribed verbatim. We conducted the interviews until no new information could be obtained and the interviewees did not address any new topics (Bowen 2006). We felt that theoretical sufficiency was reached after interviews with ten British, nine Danish and eight German physicians, as no new concepts surfaced during the last interviews.

Questions asked participants about the perceived goal of their national system, its perceived effectiveness in ensuring competence or supporting professional development and its perceived impact on clinical practice (Supplemental Appendix B). To assess the validity and feasibility of the interview protocol, we piloted it on physicians in the Netherlands, as a result of which few questions were left out or rephrased. We collected and analyzed the data in an iterative process whereby preliminary findings from the first interviews informed the structure of later interviews, leading to adjustments to the interview guide. Moreover, the collection of new data and the analysis of existing data took place simultaneously. Data were collected in the period between February and August 2017

\section{Data analysis}

After a preliminary exploratory analysis, we coded the data in an inductive process that was guided by sensitizing concepts pertinent to national physician validation systems. Adhering to the principles of grounded theory, we used the codes to build themes around participants' perceptions of national physician validation systems. Open coding of transcripts was performed independently by CS and two research assistants (C. N. and A. B.). After coding five interview transcripts, C. S. and S. M. discussed and clustered the codes that had arisen and subsequently used these for further, focused coding of interview transcripts. C. S. collated initial codes into broader themes and linked categories with subcategories (axial coding) (Charmaz 2006). C. S. and M. G. connected the themes further and reviewed the adapted coding manual used for coding of the next transcripts. C. S., M. G., F. S., G. R., and E. D. discussed codes and themes, using constant comparison of distinctive examples throughout, until C. S. had analyzed all interviews. The data analysis became more deductive towards the end when C. S., M. G., and E. D. discussed existing themes around perceptions of national physician validation systems until they reached consensus. The analysis of the last interview transcripts, the German ones, confirmed our final themes. We further validated our data by sending participants written summary notes after their interview for approval (member checking). We used the software Atlas.ti to support data analysis.

\section{Ethical approval}

All participants gave written and oral informed consent. We obtained ethical approval from the Netherlands Association for Medical Education (NVMO; file number 813).

\section{Results}

In the following subsections, we will first give an overview of the validation system of each country and describe how physicians perceived and accepted their respective system. In doing so we will focus on both differences and similarities within each country, taking into account that perceptions are the likely result of an interplay among individual, system-, and context-specific features. In a second step, we discuss participants' perceptions across validation systems, flagging differences, and similarities in perceptions across countries and distilling influencing factors which all countries share.

\section{Germany: a credit-based system}

The German system relies on the collection of credits for continuing learning and development activities. One major 
concern voiced by participants was that the educational opportunities offered were often not linked to the workplace. In their perception, this absence of workplace-based learning suggested that the system's requirements and their work were not properly aligned. Activities from which they felt they learned the most, such as daily patient encounters or case discussions, were not among the accredited options, which, according to participants, detracted from the system's authenticity. This was especially the case for hospital-based physicians, who felt that exchanging experiences or seeking advice from colleagues was much more meaningful than taking part in accredited activities.

Adding to this misalignment was the fact that physicians were free to choose their own accredited activities. Faced with a heavy workload, some physicians saw themselves forced to take courses that, however irrelevant to their practice, were held in close proximity or at a convenient time. This allowed them to fulfill their duty by ticking the required boxes, but did little to actually promote their development: "You are totally free to choose what you want. As a pulmonary physician I could go exclusively to gynaecological or dermatological events". (Participant 28, DE)

Although physicians' trust in their credit-based system had waned, they did understand such a system was needed to ensure quality of care by filtering out noncompliant physicians. However, they themselves being intrinsically motivated, they were not so much concerned about whether or not they had collected enough credits, and used the pre-set number merely as a guideline for their learning. Hence, German physicians essentially designed their continuing learning independently of the credit system. The disconnectedness between meaningful learning opportunities and the formal validation system made participants perceive the system as a tick-box exercise.

\section{Denmark: the annual dialog}

In Denmark, validation occurs through an annual dialog between the physician and his/her department head with the aim of reviewing the physician's personal or career development, rather than evaluating competence. Our interviewees greatly valued this approach, for it allowed them to customize their learning to their own needs, personal goals, and daily work. Moreover, it increased their sense of ownership and motivation to improve further. These features all bolstered the system's authenticity, causing physicians to accept the annual development dialog and even to insist on it taking place annually.

This same approach, however, also carried the inherent risk of department heads not attaching similar importance to the dialog. As the ones controlling the process, department heads wielded the power to dismiss the annual dia$\log$ as something of secondary importance. Hence, without the support of their managers, physicians were little short of disempowered:

It's a bit of a joke and it's also a bit of an issue, because I have taken it up with the head of department, that we should have this done. And he says, well that is compulsory, so it should be done. But it doesn't seem to happen. (Participant 22, DK)
Another potential risk was that the department head was unfit to evaluate daily work, affecting the credibility of feedback received and, consequently, physicians' acceptance of the validation procedure. Since feedback often appeared insignificant, Danish physicians suggested that feedback designed to evaluate their practice should actually come from peers:

The ones who should evaluate your skills should be your closest mentor, supervisor or peers who work with you in daily practice, the ones who actually know you. The annual talk with the head of your department is more for a career planning thing. They really, of course they know what you do, but I don't think that they really know your skills. (Participant 18, DK)

In a similar vein, one interviewee dubbed the annual dialog as "just a little social conversation with your boss" (Participant 13, DK). These circumstances could cause physicians to lose trust in the department head and in the system for personal development, transforming the personalized feedback dialog - if improperly performed into a tick-box exercise. As one of the participants explained:

We have so many systems controlling us in many different ways and that is not a stimulation factor in order to, to become a decent doctor. That's just another thing you have to do before you can go to bed. (Participant 20, DK)

\section{The United Kingdom: a portfolio-based revalidation system}

As briefly touched upon previously, British physicians must demonstrate their fitness to practise during annual appraisals which are guided by a portfolio that includes evidence of continuing professional development activities undertaken or feedback received, for example. During such meetings, the physicians reflect on this supporting information and, together with their appraisers, formulate a personal development plan. Our British participants recognized that the appraisal, indeed, focused on learning needs, facilitated development and helped improve practice. They felt the discussions encouraged reflection on past performance and future ambitions relevant to their practice. On the other hand, however, they sometimes perceived the obligation to document activities in the portfolio for validation purposes as bureaucratic, often saving it until the last moment:

It is a very easy process to go through with your eyes and brains half closed. So, I think the responsibility for your learning still remains very much with you. And the appraisal and the revalidation process are boxes that you have to jump through in order to achieve that. (Participant 9, UK)

What resulted critical in determining the appraisal's quality was the commitment of the appraiser. Appraisers who were most effective were dedicated, properly prepared for the appraisal, studied the personal development plan, discussed its relevance or suggested alternatives. Physicians particularly accepted appraisers whom they considered a "critical friend" who encouraged them to reflect on the relevance of activities: "So it is not just about, you know, ticking the boxes and saying that you've had all those activities. It's also about how these activities have changed your practice and your perception of things." (Participant 2, UK) In our interviewees' experience, however, such commitment was not always the rule as several appraisers 
skimmed through the portfolio in a ticking-the-box fashion, paying little regard to physicians' development. This undermined the quality and credibility of feedback received and, in turn, the physicians' trust in and respect for the appraiser: "So nobody ever looked at them to see if they're any good. I could, to be honest; I could write a whole load of rubbish." (Participant 1, UK)

Similarly, questionable peer or patient feedback could also clearly affect the system's validity. Bound by a collegial culture, physicians, rather than being critical, tended to overemphasize positive feedback. Although such feedback was flattering, our interviewees were fully aware that avoiding criticism was part of the behavioral code among colleagues. Therefore, uncritical feedback failed to induce change, or reduced physicians' trust in the systems' effectiveness.

\section{Cross-country comparison}

From our comparison of perceptions across countries, we could distill several overarching factors that influenced physicians' perceptions and acceptance of their validation system. These were: physicians' beliefs about learning, the credibility of requirements, support from supervisors or colleagues, and respect for and trust in the appraiser. What deserves first mention is the observation that all our participants, regardless of country, unanimously declared to be committed to lifelong learning and acknowledged the need for some form of validation system to stimulate continuing development, to evaluate competence for accountability purposes, and to keep their knowledge and skills up to date. On the other hand, however, participants also unanimously agreed that their country's validation system, in its current form, somewhat missed its purpose of improving practice performance or identifying physician incompetence. The mandatory requirements all three validation systems rested on bore little relation to clinical practice, leading participants to perceive their system as punitive and ineffective.

All participants reported, without exception, that they had intrinsic motivation to work on their personal development. That is, rather than complying with the physician validation requirements, most physicians mentioned that they exceeded them. Consequently, there was a general sentiment among physicians that the system was not geared towards them, but designed to monitor only a minor group of physicians who failed to meet the standards and required formal guidance. Hence, they deemed the system particularly useful during early career, for older physicians close to retiring, those working in isolated settings, or for those who would otherwise refrain from continuing learning: "Should we punish all the ambitious doctors because a few doctors just sit on the couch and watch soccer?" (Participant 20, DK)

Physicians voiced concern over the systems being disconnected from true, work-related learning and being incapable of determining actual functioning or detecting deficiencies, as testified by the opportunities available to cheat the system. More specifically, they questioned the systems' effectiveness, particularly its ability to detect "bad apples" or those unfit to practise: "If I was doctor Shipman at the moment, I would be passing the revalidation with flying colors." (Participant 1, UK)
Although a heavy workload sometimes forced physicians to favor efficiency over effectiveness, they sought to strike a balance as much as possible by choosing educational activities according to their learning needs. Nonetheless, physicians felt that most of their learning needs were largely addressed in daily practice, and that continuous development and lifelong learning were embedded in daily work. Our interviewees learned from case discussions, consulting with colleagues, giving presentations or reflecting on their work. Finally, physicians believed that a mere obligation to comply with minimum competency standards was not enough, by far, to achieve excellence and highquality patient care:

I suppose you could call it the Olympic high jump. I don't regard the entry level, that is the revalidation level, as good enough for what I'm doing. I need to be better than that, a long way better than that. (Participant 5, UK)

\section{Discussion}

The present study aimed to explore physicians' perceptions and acceptance of validation across different national physician validation systems. Our findings suggest that physician validation systems are often misaligned with daily practice, clearly jeopardizing physicians' trust in the system and inviting game playing, most notably in the form of credit collection. More specifically, the requirement to obtain a specified number of credits was conducive to boxticking behavior among physicians who sometimes saw themselves forced to select educational activities that were irrelevant to their learning needs for the sole purpose of obtaining the credits required for physician validation. These findings tie in neatly with previous research illustrating that credit-based evaluation systems may turn into a tick-box exercise, particularly when quality control is lacking (McGivern and Ferlie 2007; Chamberlain 2010; Cook et al. 2015). Drazen and Weinstein (2010), by extension, also warned of systems' clinical irrelevance and inability to support change. As our study revealed, such circumstances corroded physicians' trust in the system. Other factors that contributed to a further loss of trust in the system were the workplace culture and a lack of support. Physicians often questioned the feedback received from the validation system or cast doubt on its credibility. Instead, they preferred to consult with colleagues informally, outside the system, to inform their self-assessment, while resorting to pure game playing when it came to meeting the requirements (Lockyer et al. 2011; Brennan et al. 2017).

Despite their skepticism towards physician validation systems, physicians embraced their continuing development, an observation that finds resonance in other studies (Nielsen et al. 2002; Kjaer et al. 2014). Furthermore, physicians felt that lifelong learning was essentially achieved in their daily work, by practising, asking for or receiving feedback, and reflecting on their actions. These findings point to an evident need for a better and more meaningful alignment between physicians' practice and the system's requirements, to render more authentic and effective physician validation systems.

The challenge to overcome a lack of trust and game playing is not specific to our field of study. On the contrary, literature on industrial and organizational psychology and 
student assessment report similar difficulties in evaluating competence and supporting development. In student assessment, for instance, it has been demonstrated that students' perceptions of assessments' quality influence their approach to the assessment tasks and, consequently, their learning outcomes (Reinke 2003; Gulikers et al. 2006). Similarly, perceived fairness, meaningfulness, and practicality of the assessment all determine acceptability, while in management, performance appraisals have been reported to lack purpose, with red tape exceeding developmental achievements (Iqbal et al. 2015). In the business world moreover, there is a growing tendency to regard performance appraisals as too strict, considering that daily routine offers plenty of opportunities to gauge employees' performance (Bach 2005). Hence, the current trend to replace formal appraisals by regular informal dialogs with the aim to integrate timely feedback into daily practice.

The answer to the challenges unraveled by our findings relate to key principles of the self-determination theory (Ryan and Deci 2000). According to this theory, perceived autonomy paired with a sense of relatedness through coordinated or organizational support can help in shaping a quality culture. Such a quality culture encourages individuals to engage in procedures for continuing development such as physician validation systems driven by intrinsic motivation, thereby remaining competent and strengthening capability (Links 2018). Our interview data confirm that activities that promoted reflection and development, such as annual dialogs or appraisals, were, in effect, preferred to disciplinary measures such as formal performance evaluations and assessments (Conlon 2003; Boylan et al. 2005).

\section{Implications}

Managing tensions between accountability and development is difficult. A greater emphasis on formative components could help align the systems' requirements with physicians' beliefs about learning in the workplace, thereby strengthening physicians' motivation and their trust in validation systems (Boswell and Boudreau 2000). Moreover, accrediting workplace-based activities such as institutional group meetings or interprofessional rounds would accentuate the relevance of practice-based activities within physician validation systems (Lockyer et al. 2017). Instead of being time-based, these activities should be outcomebased, tailored to the individual's needs and practice (Frank et al. 2010). Offering regular informal dialogs to discuss relevant educational activities with a colleague or a mentor could increase systems' authenticity. This could also improve the credibility and acceptance of feedback, inducing deeper reflection on individual and group performance and creating a sense of relatedness and autonomy. Such changes could ultimately result in systems being perceived as more authentic and flexible, countering current experiences of the system being a mere tick-box exercise (Links 2018; Lockyer et al. 2017). Perhaps, then, physicians may come to perceive validation as an indispensable contributor to their continuing development, their capabilities, and quality improvement instead of regarding them as unavoidable (Kempkens et al. 2009; Blaschke 2012; Mountford and Shojania 2012; Links 2018).

\section{Limitations}

Our research design carries potential limitations. We enrolled participants across three different European countries. While we consider it a strength that we performed a cross-country comparison, physicians' perceptions of other systems may yield different results. Future research should explore systems' core characteristics beyond our setting to better understand the importance of context.

We selected participants from one single medical speciality, respiratory medicine. Other specialities may yield different results.

We invited self-selected volunteers from a pool of physicians who are involved in international activities. This selfselected group may have been more or less critical or ambitious than their colleagues.

\section{Conclusions}

For national physician validation systems to truly support lifelong learning and reliably assess competence, they need to be carefully designed and integrated into daily work. The assessment tools applied, the stakeholders involved, and the entire process determine if systems appear authentic and valuable for continuing professional development. Engaging physicians as key stakeholders in the design of those systems may cultivate a sense of relatedness fostering a culture of quality and promoting acceptance and commitment. Practising physicians' lifelong learning is the cornerstone of safe medical practice. The findings of this study underscore the need for enhanced national physician validation systems to improve authenticity and engage our physicians in a learning culture that will ultimately lift our medical systems to a state of high-quality patient care.

\section{Glossary}

National Physician Validation System: A key feature of our article, a concept also referred to as recertification, revalidation or maintenance of certification. We drew this definition from: Horsley T, Lockyer J, Cogo E, Zeiter J, Bursey F, Campbell C. 2016. National programs for validating physician competence and fitness for practice: A scoping review. BMJ Open. 6(4).

\section{Acknowledgements}

The authors wish to thank all interviewees for their contribution. Angelique van den Heuvel provided help in form of language editing, which we highly appreciated. The authors are also grateful to our two research assistants Celine Notermans and Anindita Bhattacharjee for their assistance in coding and discussing the interview transcripts.

\section{Disclosure statement}

The authors report no conflicts of interest. The authors alone are responsible for the content and writing of this article.

Sharon Mitchell is a former employee of the European Respiratory Society.

\section{Funding}

This study was funded by the European Respiratory Society. However, Carolin Sehlbach who was appointed to the research project as a PhD 
student at Maastricht University conducted the research independently.

\section{Notes on contributors}

Carolin Sehlbach, MSc, is a PhD student at the School of Health Professions Education (SHE), Department of Educational Development and Research, Maastricht University, Maastricht, The Netherlands.

Marjan J. B. Govaerts, MD, PhD, is an associate professor at the Department of Educational Development and Research, Maastricht University, Maastricht, The Netherlands.

Sharon Mitchell, MSc, is an independent researcher, fraternized with the Department of Educational Development and Research, Maastricht University, Maastricht, The Netherlands.

Gernot G. U. Rohde, MD, PhD, is a Professor and respiratory specialist at the Johann Wolfgang Goethe University Hospital, Frankfurt am Main, Germany, and former Education Council Chair of the European Respiratory Society.

Frank W. J. M. Smeenk, MD, PhD, is a Professor at the Department of Educational Development and Research, Maastricht University, Maastricht, the Netherlands, and respiratory specialist at the Catharina Hospital, Eindhoven, The Netherlands.

Erik W. Driessen, PhD, is a Professor at the Department of Educational Development and Research, Maastricht University, Maastricht, The Netherlands.

\section{ORCID}

Carolin Sehlbach iD http://orcid.org/0000-0001-9732-1377

Gernot G. U. Rohde (D http://orcid.org/0000-0002-5193-7755

Frank W. J. M. Smeenk iD http://orcid.org/0000-0003-4963-2714

\section{References}

Ahmed K, Khan RS, Darzi A, Athanasiou T, Hanna GB. 2013. Recertification: What do specialists think about skill assessment? Surgeon. 11:120-124.

Archer J, Lynn N, Roberts M, Coombes L, Gale T, de Regand Bere S 2015. A systematic review on the impact of licensing examinations for doctors in countries comparable to the UK.

Bach S. 2005. New directions in performance management. In: Bach S, editor. Managing human resources: personnel management in transition. 4th ed. New York: Blackwell Publishing. p. $289 \mathrm{ff}$.

Blaschke LM. 2012. Heutagogy and lifelong learning: a review of heutagogical practice and self-determined learning. IRRODL. 13:56-71.

Boswell WR, Boudreau JW. 2000. Employee satisfaction with performance appraisals and appraisers: the role of perceived appraisal use. Human Resource Dev Quarterly. 11:283-299.

Boulet J, van Zanten M. 2014. Ensuring high-quality patient care: the role of accreditation, licensure, specialty certification and revalidation in medicine. Med Educ. 48:75-86.

Bowen GA. 2006. Grounded theory and sensitizing concepts. Int J Qualitative Methods. 5:12-23.

Boylan O, Bradley T, McKnight A. 2005. Gp perceptions of appraisal: professional development, performance management, or both?. $\mathrm{Br}$ Gen Pract. 55:544-545.

Brennan N, Bryce M, Pearson M, Wong G, Cooper C, Archer J. 2017. Towards an understanding of how appraisal of doctors produces its effects: a realist review. Med Educ. 51:1002-1013.

Chamberlain JM. 2010. Portfolio-based performance appraisal for doctors: a case of paperwork compliance. Sociol Res Online. 15:8.
Charmaz K. 2006. Coding in grounded theory practice. In: Silverman D, editor. Constructing grounded theory. London: Sage.

Conlon M. 2003. Appraisal: the catalyst of personal development. BMJ. 327:389-391.

Cook DA, Holmboe ES, Sorensen KJ, Berger RA, Wilkinson JM. 2015. Getting maintenance of certification to work: a grounded theory study of physicians' perceptions. JAMA Intern Med. 175:35-42.

Drazen JM, Weinstein DF. 2010. Considering recertification. N Engl J Med. 362:946-947.

Dubravec M. 2011. Board certification/recertification/maintenance of certification - a malignant growth. J Am Phys Surg. 16:52-53.

Frank JR, Snell LS, Cate OT, Holmboe ES, Carraccio C, Swing SR, Harris P, Glasgow NJ, Campbell C, Dath D, et al. 2010. Competency-based medical education: theory to practice. Med Teach. 32:638-645.

Goodyear-Smith F, Whitehorn M, McCormick R. 2003. General practitioners' perceptions of continuing medical education's role in changing behaviour. Educ Health (Abingdon, England). 16:328-338.

Gulikers JTM, Bastiaens TJ, Kirschner PA, Kester L. 2006. Relations between student perceptions of assessment authenticity, study approaches and learning outcome. Studies Educ Eval. 32:381-400.

Horsley T, Lockyer J, Cogo E, Zeiter J, Bursey F, Campbell C. 2016. National programmes for validating physician competence and fitness for practice: a scoping review. BMJ Open. 6:e010368

lqbal MZ, Akbar S, Budhwar P. 2015. Effectiveness of performance appraisal: an integrated framework. Int J Manag Rev. 17:510-533.

Kempkens D, Dieterle WE, Butzlaff M, Wilson A, Böcken J, Rieger MA, Wilm S, Vollmar HC. 2009. German ambulatory care physicians' perspectives on continuing medical education - a national survey. J Contin Educ Health Prof. 29:259-268.

Kjaer NK, Steenstrup AP, Pedersen LB, Halling A. 2014. Continuous professional development for gps: experience from Denmark. Postgrad Med J. 90:383-387.

Links MJ. 2018. Beyond competency-based continuing professional development. Medical Teacher. 40:253-258.

Lipner RS, Bylsma WH, Arnold GK, Fortna GS, Tooker J, Cassel CK. 2006. Who is maintaining certification in internal medicine-and why? A national survey 10 years after initial certification. Ann Intern Med. 144:29-36.

Lockyer J, Armson H, Chesluk B, Dornan T, Holmboe E, Loney E, Mann K, Sargeant J. 2011. Feedback data sources that inform physician self-assessment. Med Teach. 33:e113-e120.

Lockyer J, Bursey F, Richardson D, Frank JR, Snell L, Campbell C. 2017. Competency-based medical education and continuing professional development: a conceptualization for change. Med Teach. 39:617-622.

McGivern G, Ferlie E. 2007. Playing tick-box games: Interrelating defences in professional appraisal. Human Relat. 60:1361-1385.

Mountford J, Shojania KG. 2012. Refocusing quality measurement to best support quality improvement: local ownership of quality measurement by clinicians. BMJ Qual Saf. 21:519-523.

Nielsen JE, Lous J, Adeler HF, Olesgaard P, Maagaard RR, Olesen F. 2002. General practitioners' continuing medical education: a prospective study from the county of aarhus. Scand J Prim Health Care. 20:198-200.

Reinke S. 2003. Does the form really matter? Leadership, trust, and acceptance of the performance appraisal process. Rev Public Personnel Administr. 23:23-37.

Ryan RM, Deci EL. 2000. Self-determination theory and the facilitation of intrinsic motivation, social development, and well-being. Am Psychol. 55:68-78.

Sehlbach C, Govaerts MJ, Mitchell S, Rohde GGU, Smeenk FWJM, Driessen EW. 2018. Doctors on the move: A european case study on the key characteristics of national recertification systems. BMJ Open. 8:e019963.

Solé M, Panteli D, Risso-Gill I, Döring N, Busse R, McKee M, LegidoQuigley H. 2014. How do medical doctors in the european union demonstrate that they continue to meet criteria for registration and licencing? Clin Med (Lond). 14:633-639. 